\title{
FREQUENCY OF MALE FACTOR AND ABNORMALITIES OF SEMEN ANALYSIS IN INFERTILE COUPLE.
}

\footnotetext{
1. FCPS

Assistant Professor (Obs \& Gyne)

Nishtar Medical University.

2. FCPS

Assistant Professor (Obs \& Gyne)

Nishtar Medical University.

3. FCPS

Senior Registrar (Obs \& Gyne)

Nishtar Medical University.
}

Correspondence Address:

Dr. Asiya Fayyaz

Assistant Professor Obs \& Gyne

Nishtar Medical University.

asiyafayyaz1998@gmail.com

Article received on:

24/10/2019

Accepted for publication:

$22 / 01 / 2020$

\begin{abstract}
Asiya Fayyaz', Shagufta Tabassum², Saima Yasmin Qadir ${ }^{3}$
ABSTRACT... Infertility is global health issue. Male factor contribute to infertility in more than half of sub fertile couples. Their diagnosis is easy by simple test of husband semen analysis. This study has been designed to know the contribution of male factor and frequency of abnormalities of semen in infertile couple. Objectives: To determine the frequency of male factor in infertile couple and to evaluate the different abnormalities in semen. Study Design: Descriptive study. Setting: Department of Obstetrics and Gynecology in Nishtar Hospital Multan. Period: From January 2019 to June 2019. Material \& Methods: Study started after taking approval from hospital ethical committee. Study included 200 subfertile couples after informed consent attending the outpatient department. The partner of female attending the fertility clinic between ages 20-40 were selected. History taken from female partner regarding age of husband, duration of subfertility, type of subfertility any drug intake and medical illness of husband. Result: Among 200 couples 64(32\%) had abnormal semen parameters24 had oligospermia. Eight had azoospermia and 60 had asthenospermia. 20 patients had teratospermia. Conclusion: Male factor is significant contributor of infertility therefore awareness is needed in order to engage more males partner in evaluation and management of infertility.
\end{abstract}

Key words: $\quad$ Asthenospermia, Azoospermia, Infertility, Oligospermia, Semen Analysis, Teratospermia.

Article Citation: Fayyaz A, Tabassum S, Qadir SY. Frequency of male factor and abnormalities of semen analysis in infertile couple. Professional Med J 2020; 27(7):14541458. DOI: 10.29309/TPMJ/2020.27.07.4280

\section{INTRODUCTION}

Infertility impacts 8 to12\% of couples worldwide with $40 \%$ attribution of male factors. ${ }^{1}$ The prevalence of infertility in Pakistan is $22 \%$ with $4 \%$ primary and $18 \%$ secondary subfertility. ${ }^{2}$ Data available reveals that in approx. $20-25 \%$ cases of infertility, pathology are found in man alone and in another $30 \%$ both man and woman were abnormal. ${ }^{3}$ In $90 \%$ cases cause of infertility can be identified and in $50 \%$ of cases, couples conceive with treatment. ${ }^{4}$ Of all the infertile couples only $15 \%$ have identifiable problem in semen parameters.

Male factor was being ignored previously but now it is no more untreatable problem. Since 1980, the fertility rate for man in their 30 s was more than $21 \%$ in contrast to the study in 2006 data showed that fertility rate in man younger than 30 years has decreased worldwide by $15 \% .{ }^{5}$ Male factor infertility is term that encompasses different conditions to sperm function that make it difficult to fertilize an egg under normal condition. ${ }^{6}$ There are many factors and medical illnesses leading to male infertility e.g. genetic causes, cryptorchidism, varicocele, orchitis, genital tract obstruction, occupation and environmental factors and iatrogenic infertility. Semen analysis is single most important investigation with sensitivity of $89.6 \%$ that is able to detect 9 out of 10 men with genuine problem of infertility. ${ }^{7}$ In order to establish evidence based reference values for semen analysis WHO 2010 manuals describe limit of normal volume are $1.5 \mathrm{ml}$, total sperm count 15 milion/ $\mathrm{ml}$, progressive motility of $40 \%$ viability $58 \%$ and normal form of $4 \%$. Screening for anti-sperm antibodies is not included in this value as there is no evidence for its effective treatment to improve fertility. Oligospermia is used to describe seminal fluid analysis where concentration of spermatozoa is below the lower reference value. Asthenospermia is spermatoozoa 
with poor motility and teratospermia is abnormal morphology for given reference value. Our social stigma is that society only blame female for infertility. From this study we could know the incidence of male factors in this area so that we can involve them and educate them on the treatment of particular issue. Male partner often believe as they have no sexual dysfunction so they cannot be responsible for infertility. This study has been designed to know the contribution of male factors and frequencies of different abnormalities in infertile couple. Researchers have shown that early diagnosis and treatment are necessary to mitigate these problems which are associated with male infertility.

\section{MATERIAL \& METHODS}

This was prospective study of seminal fluid parameters of infertile couple. This study was conducted in Department of obstetrics and gynecology for a period of six months from $1^{\text {st }}$ January 2019 to $31^{\text {th }}$ June 2019. Study started after taking approval from hospital ethical committee. Study included 200 subfertile couples after informed consent attending the outpatient department. The partner of female attending the fertility clinic between ages 20-40 were selected. History taken from female partner regarding age, duration of subfertility, type of subfertility any drug intake and medical illness of spouse. Detail instructions were given for semen collection like abstinence of 3-5 days and sample collected in sterile pipette by masturbation technique. One laboratory was selected to avoid inter laboratory variation. All the information was recorded in specially designed Performa. All the couples whose report of semen analysis not available and who never consented were excluded from study. The semen was analyzed for volume, number of spermatozoa in one $\mathrm{ml}$, motility and morphology of spermatozoa. For comparison of data WHO reference value 2010 was used. Data gathered was analyzed by SPSS 21. Descriptive statistics were calculated in frequency, mean \pm SD. Data was collected for age, years of sub fertility and type of sub fertility and presented in frequency and percentages and mean \pm SD.
Semen analysis is the cornerstone of laboratory evaluation of infertile couples. 200 samples of infertile couples were analyzed. 128 couples have primary subfertility and 72 had secondary subfertility as shown in Figure-1. Regarding age distribution 88 patients were age between 22-30years while 112 patients were of age 31-40. So the mean age of this group is 32 . Demography in terms of age, duration of sub fertility and type of sub fertility shown in Figure1. Mean age of duration of subfertility is 3.7 years. All the samples were analyzed according to WHO criteria 2010 among which 64 had abnormal semen analysis. We also compared the different abnormalities in semen analysis reports and results are given in tabulated form.

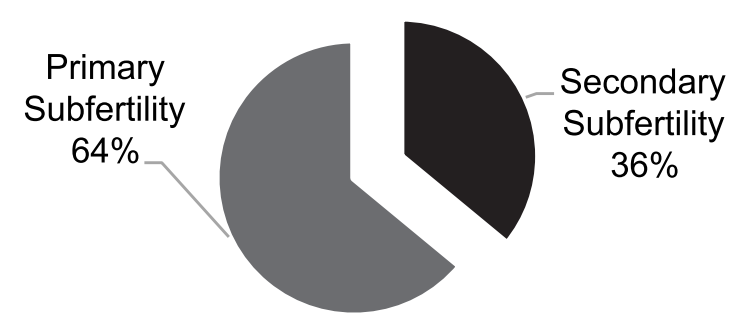

Secondary Subfertility Primary Subfertility

Figure-1. Type of infertility $(n=200)$.

178

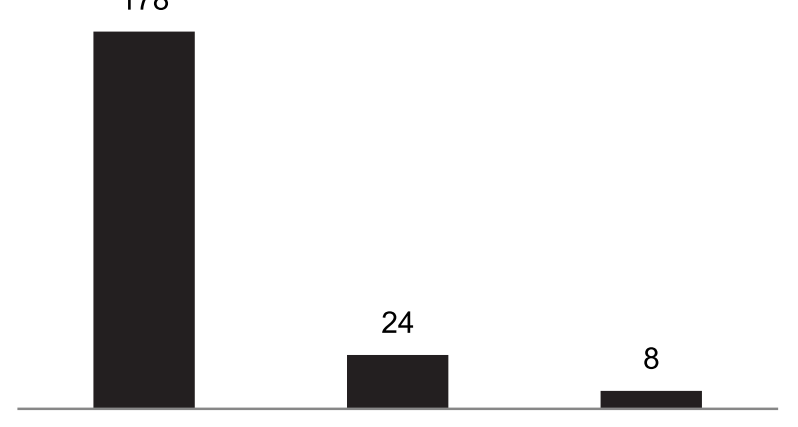

NORMOSPERMIA OLIGOSPERMIA AZOOSPERMIA

Figure-2. Classification based on Sperm Count $(n=200)$

\begin{tabular}{|c|c|c|c|c|}
\hline \multirow{2}{*}{ Age } & \multicolumn{2}{|c|}{ 21-30yrs } & 88 & $44 \%$ \\
\hline & \multicolumn{2}{|c|}{ 30-40yrs } & 118 & $48 \%$ \\
\hline \multicolumn{5}{|c|}{ Table-I. Age distribution $(n=200)$. } \\
\hline \multicolumn{2}{|c|}{ Motility } & \multicolumn{2}{|c|}{ No. of Patient } & Percentage \\
\hline \multicolumn{2}{|l|}{ Normal } & \multicolumn{2}{|c|}{140} & 70.00 \\
\hline \multicolumn{2}{|c|}{ Asthenospermia } & \multicolumn{2}{|c|}{60} & 30.00 \\
\hline
\end{tabular}

\section{RESULTS}




\begin{tabular}{|l|c|c|}
\hline \multicolumn{1}{|c|}{ Motility } & No. of Patient & Percentage \\
\hline Normal & 180 & 90.00 \\
\hline Teratospermia & 20 & 10.00 \\
\hline
\end{tabular}

Table-III. Classification based on morphology.

\begin{tabular}{|l|c|c|}
\hline \multicolumn{1}{|c|}{ Abnormality } & No. Of Patient & Percentage \\
\hline Oligospermia & 24 & 37.50 \\
\hline Azoospermia & 8 & 12.50 \\
\hline Asthenospermia & 60 & 93.75 \\
\hline Teratospermia & 20 & 31.25 \\
\hline
\end{tabular}

Table-IV. Comparison of different abnormalities in semen analysis.

\section{DISCUSSION}

Infertility is global reproductive health care issue and its social and psychological consequences cannot be ignored. As per the WHO estimates 60-80 million couples in world suffered from subfertility. ${ }^{7}$ One in every four couples in developing country has been found to be affected by infertility. In our gynecologic clinics almost half patients presents with subfertility. According to WHO survey from 1990 to 2004 infertility affects $15 \%$ couple globally. In present study $64 \%$ were of primary sub fertility and $35.20 \%$ cases were of secondary subfertility. Ten year study in India showed $74.7 \%$ cases had primary sub fertility, both studies showed that primary sub fertility is more than two times. ${ }^{11}$ In contrast four year study conducted in Nigeria showed $70 \%$ patients had secondary sub fertility and $30 \%$ had primary sub fertility. ${ }^{12}$

Reports of Semen analysis give us indication on testicular function and integrity of male genital tract which guide us for treatment plan. It also guides to fertility and not a certain proof of fertility of an individual except in cases of azoospermia where cumulative conception rate is zero. ${ }^{13}$ The study highlighted that male factor exclusively contribute about $32 \%$ to subfertility. In study conducted in Nigeria showed male factor in $52.38 \%$. A randomized clinical trial told $40 \%$ attributed to male factor ${ }^{1}$. A large study comprise of ten years told male factor identified in $23.9 \%$ and abnormality in semen analysis in $22.7 \%$ and sexual dysfunction in $1.2 \%$ only. ${ }^{13}$ Similarly another study showed male infertility in $40 \%$ subfertile couples. ${ }^{14}$ The study by KoboriY tells male factors infertility in $50 \%$ of couples. ${ }^{15}$

In our study $44 \%$ cases were age group 20-30 years and $46 \%$ were of age group $30-40 \%$. In study conducted in Nigeria age of male partner is 30-60 years with mean of 31 years. ${ }^{16}$ In study conducted by Abrain A and Aziz M in India ${ }^{17}$ it was found that majority of infertile men were within the age interval of 26-30 years. As already discussed fertility rate in men younger than age 30 has decreased worldwide. ${ }^{5}$

In present study $84 \%$ cases had normospermia, $12 \%$ cases had oligospermia and $4 \%$ cases had azoospermia. Thisstudy wascompareableto study conducted in Jinnah Postgraduate medical center semen abnormality was found in 30\% cases and oligozoospermia in 5\% and azoospermia in 1.7\% cases. ${ }^{18}$ Similarly studies conducted in Nigeria $52.38 \%$ of male partner were normospermic while $26.98 \%$ and $20.64 \%$ were azoospermic and oligospermic respectively. ${ }^{19} \mathrm{~A}$ comparative study conducted in $\mathrm{NIH}$ Pakistan showed oligospermia in $23.2 \%$ and azoospermia in $13.3 \%$ asthenzoosperia in $10.5 \%$ and teratospemia in $2.4 \% .{ }^{20}$ In contrast in study conducted in Dow Medical College $50.83 \%$ males were found to have infertility. Oligoteratozoospermia was observed as predominant cause of infertility. ${ }^{21}$

Primary function of spermatozoa is the delivery of male pronuclus to fertilize egg to enable to undertake complex function involved $a$ in the process of fertilization. A human spermatozoon has developed a highly specialized morphology with its various structural components tailored to specific functional contribution.

The presence of human spermatozoa was first described over 30 years by Van leeuwehock. In present study over $90 \%$ had normal morphology and $10 \%$ had teretospermia. In a study by Adenjii RA et al most common multiple factors abnormality in the study population had astheno/ oligospermiai.e $25.5 \%$ while 3defects oligo/ astheno/teratospermia were noticed in $13.1 \%$ of the subject. ${ }^{22}$ 
In our study we also compared different abnormalities in semen and found asthenospermia is most common abnormality and occur in $60 \%$ patients and oligospermia in $37.5 \%$, teratospermia in $31.5 \%$ and azoospermia in $12.5 \%$. In cotrast A study of 1186 male in Yasmin clinic in Jakarta showed most common abnormality is oligozospermia(39.7\%) followed by azoospermia(24.4\%), teratozospermia (2.6\%) and Asthenospermia (5.9\%). ${ }^{23}$ This is compareable to study conducted by kitporntheanunt $\mathrm{M}$ et-al showed asthenoteratospermia is most common finding i.e. 84\% among all abnormalities in semen, oligoasthenoteratospermia occur in $10.7 \%$ and $4 \%$ had teratospermia. ${ }^{24}$

In summary abnormal semen quality remains a significant contribution to overall infertility in our environment among all abnormalities asthenospermia is most common.

\section{CONCLUSION}

Male factor solely contribute about $32 \%$ to subfertility among them asthenospermia is most common. The limitation of this study is to find cause of different abnormalities in semen parameters and to find the cause effect relationship. We have to find the geographic and environmental effects also.

Copyright(C 22 Jan, 2020.

\section{REFERENCES}

1. Wendie Robbins, Howard Kim, Justin Houman, GengWei Lee, Randomized clinical trial: Effect of walnuts on semen parameters and male fertility (P18-04219), current developments in nutrition, Volume 3 , Issue Supplement 1, June 2019, nzz039.P18-042-19, https://doi.org/10.1093/cdn/nzz039.P18-042-19

2. Ali, S., Sophie, R., Imam, A.M. et al. Knowledge, perceptions and myths regarding infertility among selected adult population in Pakistan: A crosssectional study. BMC Public Health 11, 760 (2011) doi:10.1186/1471-2458-1

3. Shaheen, Riffat \& Subhan, Fazli \& Sultan, Sikandar \& Subhan, Khaula \& Tahir, Faheem. (2010). Prevalence of infertility in a cross section of Pakistani population. Pakistan J. Zool. 42. 389-393.
4. Callahan $L T$, Caughey $A B$, Blue print obstetrics and gynecology. Lippincott Williams \& Wilkins; 2008 Infertility and assisted reproductive technologies; pp.275-289.

5. Martin JA, Hamilton BE, Sutton PD, et al. Births: final data for 2006. Natinal vital statics reports. 2009; 57:1101.

6. Isiah D Harris, Carolyn Fronczak, Lauren Roth, Randall B Meacham. Rev Urol. 2011; e184-e190 (4).

7. Calverton, Maryland, USA: ORC Macro and the World Health Organization; 2004. World Health Organization. Infecundity, infertility and childlessness in developing countries. DHS Comparative report no.9.

8. Jimoh AA, Olawuy TS, Omotoso GO, Oyewopo AO, Dare JK. Semen parameters and hormone profile of men investigated for infertility at midland fertility centre, Ilorin, Nigeria. J Basic Appl Sci. 2012; 8:110-3. [Google Scholar].

9. Emeakaroha MC, Obi RK, Nwanebu FC, Ogbulie JN, Uwaezuoke JC, Ohalete CN. Antibiotic sensitivity pattern of bacterial isolates from semen of men with infertility problem. World J Pharm Pharm Sci. 2012; 1:1198-20. [Google Scholar].

10. Momoh AR, Idonije BO, Nwoke EO, Osifo UC, Okhai $O$, Omoroguiwa $A$, et al. Pathogenic bacteria-a probable cause of primary infertility among couples in Ekpoma. J Microbiol Biotech Res. 2011; 1: 66-71. [Google Scholar].

11. Vasan SS. Semen examination and interpretation of the report. In: Rao KA, Srinvas MS. Laboratory manual in assisted reproductive technology. New Delhi; Jayee Brothers Medical Publishers (p) LTD; 2006.3-41.

12. Owolabi $A$, Faubaa $O B, O$ gunniyi SO. Semen quality of male partners of infertile couple in lle-Ife, Nigeria. Niger JClin Pract 2013; 16:37-40.

13. Tamarakar SR, Bastakoti R. Determinants of infertility in couples. J Nepal Health Res Counc. 2019 Apr 28; $17(1) ; 85-89$.

14. De Jonge C, Barrat CLR: The present crisis in male reproductive health: An urgent need for a political, social and research roadmap. Andrology. 2019 jun 26,:doi:10.1111/andr.12673.

15. Kobori Y: Home testing for male factor infertility: A review of current options. Fertil Steril. 2019 may; 111(5). 
16. Peter AO, Temi AP, Olufemi AP, Simidele OM, Adeniran AS. Pattern of semen parameters and factors associated with infertility in male partners of infertile couples in Nigeria. Andrology (Los Angel). 2016;5(161):21670250 .

17. Abrari A, Aziz M. Semen analysis profile in male infertility: An experience with 100 cases. India J Pathol Microbiol 2003; 46:4.

18. Sheikh R,Fatima N, lqbal S: Abnormalities of semen in infertile couple. J. Surg Pak Oct -Dec 2015; 20(4):1237.

19. Ugwa EA, Ashimi A, Abubakar M, Obadire S. Poor semen parameters among infertile couples presenting at a gynaecological clinic of Federal Medical Centre Birnin Kudu North-west Nigeria. Nigerian medical journal: journal of the Nigeria Medical Association. 2015 Jul;56(4):283.

20. Khan MS,Deepa F, Ahmed Z,Tahir F khan MA, Assessment of male reproductive health by conventional method of semen analysis; J Ayub Med Coll Abottabad: Jan-March 2011; 23(1):84-8.
21. Siddiqui QA. Semen. Profile of infertile males attending private infertility clinic of metropolitan city of Pakistan. J Dow Uni Health Sci Sep-Dec 2018; 12(3): 91-5.

22. Adenjii RA Olayernii O, OkunlolaMA,Aimakhu CO. Pattern of semen analysis of male partner $s$ of infertile couple at the University college Hospital, Ibadan wet Afer Med 2003; 243-5 SN Aulia et al 2017 J.Phys.:Conf.Ser.884 012138.

23. Aulia SN, Lestari SW, Pratama G, Harfief AK, Sumapraja K, Hestiantoro A, Wiweko B. The Pattern of abnormalities on sperm analysis: A study of 1186 infertile male in Yasmin IVF Clinic Jakarta. In journal of physics: Conference Series 2017 Aug (Vol.884, No. 1, p.012138). IOP Publishing.

24. Kitporntheranunt M, Om-songkram S,Srichawana K. Abnormal semen of infertile couple at HRH Maha Chakri Sirindhorn Medical Center. J Med Assoc Thai.2015 Nov; 98 suppl 10:S8-12.

\begin{tabular}{|c|c|c|c|}
\hline \multicolumn{3}{|c|}{ AUTHORSHIP AND CONTRIBUTION DECLARATION } \\
\hline Sr. \# & Author(s) Full Name & \multicolumn{1}{|c|}{ Contribution to the paper } & Author(s) Signature \\
\hline 1 & Asiya Fayyaz & $\begin{array}{l}\text { Data collection, Study design, } \\
\text { Interpretation, Principal } \\
\text { investigator, Final reading. } \\
\text { Data collection, Study design, } \\
\text { Interpretation, Principal } \\
\text { investigator, Final reading. } \\
\text { Data collection, Study design, } \\
\text { Interpretation, Investigator. }\end{array}$ \\
\hline
\end{tabular}

